\title{
Risk Factors for Hepatocellular Carcinoma in India
}

\author{
Premashis Kar \\ Department of Medicine, Maulana Azad Medical College, University of Delhi, New Delhi 110002, India
}

\begin{abstract}
Hepatocellular carcinoma (HCC) is an important cause of death all over the world, more so in Asia and Africa. The representative data on epidemiology of HCC in India is very scanty and cancer is not a reportable disease in India and the cancer registries in India are mostly urban. 45 million people who are suffering from chronic Hepatitis $B$ virus $(\mathrm{HBV})$ infection and approximately 15 million people who are afflicted with chronic Hepatitis $\mathrm{C}$ virus (HCV) infection in India. HBV and HCV infection is considered an important etiologic factor in HCC. Positive association between HCC and consumption of alcohol where alcohol contribute as a cofactor for hepatotoxins and hepatitis viruses. Aflatoxin contamination in the diets, Hepatitis B virus infection and liver cirrhosis in Andhra Pradesh, India and direct chronic exposure to aflatoxins was shown to cause liver cirrhosis. Cirrhosis of liver of any cause lead to develop about $70 \%-90 \%$ of HCC. Aflatoxin interact synergistically with Hepatitis B virus (HBV)/Hepatitis C virus $(\mathrm{HCV})$ infection which increase the risk of $\mathrm{HCC}$. HBV infection, $\mathrm{HBV}$ infection with Aflatoxin exposure, viral infection and alcohol consumption leading to overt cirrhosis of the liver, alcohol consumption leading to cirrhosis of the liver with viral infection are the predominant risk factor for the development of HCC. HCV and alcohol are also associated with HCC in India. Indians develop diabetes at younger age, Asians have strong genetic susceptibility for type II diabetes. Diabetes mellitus is identified as a risk factor for HCC. Prevention of viral infection by universal vaccination against hepatitis virus, HCC surveillance program, preventing alcoholic liver diseases, fungal contamination of grains and ground crops to prevent basically Aflatoxin exposure are important measures to prevent liver diseases and HCC among those at risk. (J Clin Exp Hepatol 2014;4:S34-S42)
\end{abstract}

\section{WHAT ARE THE RISK FACTORS FOR HEPATOCELLULAR CARCINOMA IN INDIA?}

$\mathrm{H}$

epatocellular carcinoma (HCC) is an important cause of death all over the world, more so in Asia and Africa. ${ }^{1}$ Chronic viral hepatitis as an important etiologic risk factor in the causation of HCC, especially in endemic areas has been reported. ${ }^{2,3}$ Nearly 45 million people are suffering from chronic Hepatitis B virus (HBV) infection and approximately 15 million people are with chronic Hepatitis $\mathrm{C}$ virus (HCV) infection in India. Hepatitis B virus is known to cause genomic integration in the liver tissue resulting in chromosomal deletions and in turn metaplasia. The p53 tumor suppressor gene can be altered in HCC under the

Keywords: risk factor, HCC, aflatoxin

Received: 11.6.2013; Accepted: 19.2.2014; Available online 13.4.2014

Address for correspondence: Premashis Kar, Director Professor of Medicine \& Gastroenterologist, Department of Medicine, Maulana Azad Medical College, University of Delhi, New Delhi 110002, India. Tel.: +91 (0) 9811042164, +91 (0) 9968604270 (mobile); fax: +91 (0) 1123230132 (O) E-mail: premashishkar@gmail.com

Abbreviations: AFB1: aflatoxin B1; DM: diabetes mellitus; GT: glucose tolerance; HBsAg: hepatitis-B surface antigen; HBV: Hepatitis B virus; HCC: hepatocellular carcinoma; HCV: Hepatitis $C$ virus; IARC: International Agency for Research on Cancer; NAFLD: non-alcoholic fatty liver disease; RR: relative risk

http://dx.doi.org/10.1016/j.jceh.2014.02.155 transactivating potential of the $\mathrm{HBx}$ protein. ${ }^{4-6}$ Chronic Hepatitis $\mathrm{C}$ virus infection is now considered an important etiologic factor in HCC. ${ }^{7}$ HCV-related carcinogenesis is possibly related to chronic inflammation and cirrhosis. ${ }^{8}$ Nalpas et al $2001^{9}$ reported a positive association between HCC and consumption of alcohol in which alcohol works as a cofactor for hepatotoxins and hepatitis viruses.

Chronic alcoholism is also on the rise in India. Guptan et al $1996^{10}$ reported that although the possible role of these viral infections and alcohol in the causation of HCC has not been assessed in detail but nearly $25 \%$ of all HBV-related chronic liver disease in India is caused by mutant forms of HBV. ${ }^{10}$

HBV infection is the predominant risk factor for the development of HCC, often related to mutant forms of HBV in India. Chronic hepatitis B or C, alcohol, obesity (non-alcoholic fatty liver disease), aflatoxin (cofactor with HBV), tobacco, tyrosinosis, hemochromatosis (iron overload), $\alpha 1$-antitrypsin deficiency, autoimmune chronic active hepatitis, primary biliary cirrhosis, alcoholic cirrhosis, nonalcoholic steatohepatitis, diabetes, viral load, male sex, older age, exposure to aflatoxins, concurrent alcohol abuse are the main risk factors for HCC has been reported by World Gastroenterology Organization: global guidelines. ${ }^{11}$

The most important factor responsible for the development of hepatocellular carcinoma in the predominant 
north Indian population is chronic Hepatitis B virus infection, with tumors developing more often in a cirrhotic (76\%) than in a non-cirrhotic liver has been reported in a prospective comprehensive study from the Indian subcontinent. This pattern is supported by quite similar study from areas where HBV infection is endemic, such as the far east and sub-Saharan Africa. A positive association of cirrhosis of the liver in $80-90 \%$ of patients with HCC has been demonstrated in reports from Northern regions. ${ }^{12-17}$ Oka et al. $1990^{18}$ found the yearly incidence rate of HCC in cirrhotics varies from $3 \%$ in the West ${ }^{19}$ to as high as $11 \%$ in Japan. Tsukuma et al1990 ${ }^{8}$ in a prospective study from Japan reported liver cirrhosis and viral hepatitis as risk factors for HCC, each carrying a 3-year cumulative risk of 12.5 and $3.8 \%$, respectively. Colombo et al $1991^{19}$ described that the development of HCC during the course of cirrhosis is not necessarily related to endstage liver disease. Cirrhotic liver contains various kinds of hepatocellular nodules and these nodules were known to cause HCC. . $^{20,21}$

Alcohol consumption has been implicated as a risk factor for developing HCC in many studies. ${ }^{22}$ Fifteen of HCC patients had a history of chronic alcohol abuse and nearly $80 \%$ of them had evidence of concomitant HBV or HCV infection. A high prevalence of HBV and HCV in alcoholic patients with HCC was demonstrated by Paterlini et al 1993. ${ }^{5}$ Alcohol seems to be a cocarcinogen in the pathogenesis of HCC, by inducing cirrhosis, and by increasing the risk of viral infections ( $\mathrm{HBV}$ and $\mathrm{HCV}$ ), as well as via its effects on P450 mixed function oxidase system, thus causing enhanced activation of chemical carcinogens. ${ }^{5}$

Ozturk et al $1991^{23}$ described Aflatoxin has been shown to cause hepatocarcinogenesis by a guanine-to-thymidine mutation at the third base of codon 249 in the p53 tumor suppressor gene. The risk of HCC is highest when Aflatoxin exposure is associated with the presence of HBsAg, suggesting a viral-chemical interaction. ${ }^{24,25}$

The predominant factor responsible for the development of HCC in India is chronic HBV infection. ${ }^{26} \mathrm{~A}$ fair proportion of HCC patients in India are either HBeAg negative or have undetectable HBsAg. Three quarters of the HCC patients in the population had distinct features of underlying cirrhosis. It is also reported that the people who have Hepatitis B virus face up to a 100-fold increased risk of developing HCC. ${ }^{27}$ Edman et al $1980^{28}$ defined that HBsAg which is present in the people infect with hepatitis virus is known to play important role in developing HCC. Ishikawa et al $2009^{29}$ described oncogenes such as c-myc activation in presence of HBsAg since it transform nontumorigenic cell lines into lines capable of growing as tumors in nude mice. It was supported by the hypothesis that HBsAg play an important role in pathogenesis of HBV-associated liver cancer. ${ }^{29}$

Several studies have also suggested that diabetes mellitus may alter the risk of developing a variety of cancers, and the associations are biologically plausible. ${ }^{30}$ Diabetes is associated with alterations in liver metabolism and immune response that may influence postoperative recovery and long-term survival after hepatectomy for cancer. ${ }^{31}$ Cancer patients who already have diabetes have a greater chance of dying of the disease than cancer patients who do not have the blood-sugar disorder. ${ }^{32}$ The risk of liver cancer is common in people with diabetes who are heavy drinkers and who may or may not have hepatitis. Insulin made by the pancreas moves through the portal vein to the liver and exposes the liver to high levels of the insulin hormone. Non-alcoholic fatty liver disease, cirrhosis and abnormal fat retention are diabetes related factors that increase the risk of liver cancer. Obesity is a shared risk factor for both diabetes and liver cancer. ${ }^{33,34}$

\section{ARE INDIANS GENETICALLY MORE PRONE TO HEPATOCELLULAR CARCINOMA?}

The representative data on epidemiology of HCC in India is not available. Cancer is not a reportable disease in India and the cancer registries in India are mostly urban. Several etiologic factors including hepatitis viruses, alcohol and aflatoxin have been implicated in the pathogenesis of hepatocellular carcinoma (HCC). There is, however, limited information from the Indian subcontinent. ${ }^{26}$ Chronic Hepatitis $C$ virus infection is possibly related to chronic inflammation and cirrhosis ${ }^{7}$ now considered an important etiologic factor in HBV-negative HCC cases. ${ }^{8}$ A positive association between HCC and consumption of alcohol has been reported from some countries. However, alcohol probably works as a cofactor for hepatotoxins and hepatitis viruses. Viral infection and chronic alcoholism may contribute to alteration in terms of mutation in genome at molecular level. ${ }^{9}$

In India HBV infection, overt cirrhosis of the liver, HCV and alcohol is the predominant factor for the development of HCC. ${ }^{26}$ Asians have a strong genetic susceptibility for type II diabetes ${ }^{35}$ and DM is a risk factor for HCC in India.

Infection with $\mathrm{HBV}$ and $\mathrm{HCV}$ are the major risk factors for the development of HCC in Indian patients. Presence of HBV antibodies even in the absence of HBsAg conferred increased risk for HCC in the presence or absence of cirrhosis. Anti-HCV positivity in the absence of $\mathrm{HCV}$ RNA conferred no increased risk. HCV RNA positivity and heavy alcohol use significantly increased the risk of HCC among cirrhotic patients, but not non-cirrhotic patients. ${ }^{36}$ The association of HBV and HCV as risk for hepatocellular carcinoma and their interaction with genetic factor needs to be further explored in our country.

Genetic variant in low penetrance gene such as GSTM1 and GSTT1 is associated with an increased risk of liver cancer. The influence of GSTM1/T1 null genotypes may contribute in the etiology of HCC in patients with higher levels of AFB1-N7-guanine adducts, who are heavy smokers and those who consume alcohol. ${ }^{37,38}$ 
Genotype D is the most common genotype in HBVassociated HCC as reported from different series. ${ }^{39}$ The $\beta$-catenin pathway appears not to be significantly involved in HBV-related HCC in India. The very low frequency of TP53 mutation suggests low levels of Aflatoxin B1 exposure. $^{40}$

Because of the discrepant and isolated reports on genetic risk factors for HCC it can be concluded that currently data is insufficient to implicate any genetic risk factor for HCC in India.

\section{WHAT ARE THE REGIONAL DIFFERENCES OF RISK FACTORS FOR HEPATOCELLULAR CARCINOMA IN INDIA?}

Hepatocellular carcinoma (HCC) is an important cause of death in Asia and Africa. ${ }^{1} \mathrm{HBV}$ and HCV are the major risk factors for HCC in Northern India. Presence of any $\mathrm{HBV}$ marker (HBsAg positive or presence of $\mathrm{HBV}$ antibodies even in absence of HBsAg) increases the risk of HCC. Kumar et al $2007^{36}$ investigated the risk of various causative agents among HCC patients without cirrhosis. Table 1 shows among the HCC patients without cirrhosis, $63.46 \%$ were positive for $\mathrm{HBV}$ markers, $1.92 \%$ for $\mathrm{HCV}$ markers and none had markers for both. History of heavy alcohol intake was found in $9.62 \%$. HCV RNA positivity and heavy alcohol use significantly increased the risk of HCC among cirrhotic patients, but not non-cirrhotic patients. ${ }^{36}$

India, one of the most populous developing countries in which chronic alcoholism is on the rise. Furthermore, it has been shown earlier that nearly $25 \%$ of all HBV-related chronic liver disease in India is caused by mutant forms of HBV. ${ }^{10}$

A North Indian study carried out in Delhi by Sarma et al $2012,{ }^{41}$ revealed that Patients of chronic HBV infection followed by chronic HCV infection were at higher risk of developing HCC in India. Chronic alcohol consumption was found to be a risk factor in cirrhotic cases only when it was associated with HCV RNA positivity. Most of the patients had a large tumor size $(>5 \mathrm{~cm})$ with multiple liver nodules, indicating an advanced stage of the disease thus making curative therapies difficult. ${ }^{41}$

In another North Indian study carried out in AIIMS, Delhi by Paul et al $2007^{42}$ suggested that the incidence of HCC among patients with liver cirrhosis was intermediate, being lower than that in Japan but higher than that reported from Europe.

Tripathy et al $2009^{43}$ suggested that among the western Indian population, certain HLA alleles or associated haplotype influence $\mathrm{HCV}$ infection as a host genetic factor. ${ }^{43}$

In a South Indian study by Anitha et al $2011^{44}$ revealed the chronic exposure to aflatoxin is a cause of liver cirrhosis.

The major risk factor for the development of HCC is cirrhosis of the liver due to HBV \& $\mathrm{HCV}$ infection (Table 2). However, about one quarter of HCC cases diagnosed in India do not have any known predisposing risk factors. The major known risk factors for HCC are viral (chronic hepatitis B and hepatitis C), toxic (alcohol and aflatoxins), metabolic (diabetes and non-alcoholic fatty liver disease, hereditary hemochromatosis) and immune-related (primary biliary cirrhosis and autoimmune hepatitis).

Approximately, three fourths of all liver cancer deaths are attributed to hepatitis B infection worldwide. In India the hepatitis-B surface antigen ( $\mathrm{HBsAg})$ positivity in patients with HCC varies from $36 \%$ to $74 \%$ (mean of 47\%). ${ }^{45}$ Underestimation of HBV infection in Indian patients with cirrhosis is likely due to the wide variability in the testing methodology. The relative risk of developing HCC in Indian patients with chronic HBsAg infection was estimated to be 17.89 from various studies. ${ }^{36}$

A small proportion of Indian patients with chronic liver disease or HCC have combined HBV and HCV infections. Contamination of food with Aflatoxin is common in

Table 1 Distribution of HCC Patients with and without Cirrhosis According Major Risk Factors. ${ }^{36}$

\begin{tabular}{|c|c|c|c|c|}
\hline \multirow[t]{2}{*}{ Risk factor } & \multicolumn{2}{|c|}{ HCC with cirrhosis $(n=137)$} & \multicolumn{2}{|c|}{ HCC without cirrhosis $(n=52)$} \\
\hline & $n(\%)$ & OR (95\% CI) & $n(\%)$ & OR (95\% CI) \\
\hline \multicolumn{5}{|l|}{ HBV status } \\
\hline Any marker+ & $97(70.80)$ & $48.90(24.61-97.19)$ & $33(63.46)$ & $35.03(15.59-78.66)$ \\
\hline HBsAg+ve, antibody+ve & $85(62.04)$ & $39.88(19.41-81.97)$ & $26(50.00)$ & $24.40(10.60-56.18)$ \\
\hline HBsAg - ve, antibody-ve & $12(8.76)$ & $12.10(2.67-54.88)$ & $7(13.46)$ & 19.60 (3.94-97.39) \\
\hline \multicolumn{5}{|l|}{ HCV status } \\
\hline Anti-HCV+ve overall & $22(16.06)$ & 7.91 (3.12-20.03) & $1(1.92)$ & $0.81(0.09-6.88)$ \\
\hline Anti-HCV+ve, HCV RNA+ve & $18(13.14)$ & $7.53(2.73-20.78)$ & $1(1.92)$ & $0.97(0.11-8.54)$ \\
\hline Anti-HCV-ve, HCV RNA-ve & $4(2.92)$ & $7.61(0.84-68.77)$ & 0 & - \\
\hline \multicolumn{5}{|l|}{ Heavy alcohol use } \\
\hline$+v e$ & $25(18.25)$ & 3.32 (1.70-6.47) & $5(9.62)$ & $1.58(0.55-4.53)$ \\
\hline
\end{tabular}


Table 2 Estimates of the Attributable Fractions of Cirrhosis and Hepatocellular Carcinoma due to Infection with HBV and HCV by Different Parts of World Including India (SEAR-B \& SEAR-D). ${ }^{94}$

\begin{tabular}{|c|c|c|c|c|c|c|}
\hline \multirow[t]{2}{*}{ Region } & \multicolumn{3}{|c|}{ Attributable fractions of cirrhosis } & \multicolumn{3}{|c|}{ Attributable fractions of HCC } \\
\hline & HBV (\%) & HCV (\%) & Combined (\%) & HBV (\%) & HCV (\%) & Combined (\%) \\
\hline AFR-D/E & 44 & 16 & 60 & 47 & 18 & 65 \\
\hline AMR-A & 5 & 42 & 47 & 16 & 48 & 64 \\
\hline AMR-B/D & 8 & 23 & 31 & 43 & 21 & 64 \\
\hline EMR-B & 35 & 36 & 71 & 59 & 13 & 72 \\
\hline EMR-D & 27 & 51 & 78 & 26 & 47 & 73 \\
\hline EUR-A & 13 & 38 & 51 & 18 & 44 & 62 \\
\hline EUR-B/C & 25 & 34 & 59 & 51 & 15 & 66 \\
\hline SEAR-B & 28 & 30 & 58 & 37 & 27 & 64 \\
\hline SEAR-D & 26 & 14 & 40 & 47 & 28 & 75 \\
\hline WPR-A & 14 & 62 & 76 & 25 & 66 & 91 \\
\hline WPR-B & 57 & 21 & 78 & 65 & 18 & 83 \\
\hline World & 30 & 27 & 57 & 53 & 25 & 78 \\
\hline
\end{tabular}

[(AFR, African; AMR, The Americas; EMR, Eastern Mediterranean; EUR, European; SEAR, South-East Asian; and WPR, Western Pacific), as defined in the GBD 2000 project. Each region is designated by the three- or four-letter region code followed by a one-letter suffix, corresponding to the mortality pattern of its member countries: $\mathrm{A}=$ very low child, low adult mortality; $\mathrm{B}=$ low child, low adult mortality; $\mathrm{C}=$ low child, high adult mortality; $\mathrm{D}=$ high child, high adult mortality; and $\mathrm{E}=$ high child, very high adult mortality].

tropics. Foodstuffs commonly contaminated with Aflatoxin include maize, paraboiled rice, coconut kernel, and groundnuts. Aflatoxin has been associated with toxic hepatitis and Indian childhood cirrhosis but there are no Indian studies on its role in HCC. The highest incidence reports of HCC are in Asia and sub-Saharan Africa. ${ }^{46,47}$ According to the International Agency for Research on Cancer (IARC) in 2002, ${ }^{48}$ worldwide incidence ratios were 15.8 cases per 100,000 per year for men and 5.8 cases per 100,000 per year for women. The highest incidence regions in Asia and Africa have a high prevalence of chronic hepatitis $B$ as well as significant exposure to dietary aflatoxins. ${ }^{49}$ The risk of HCC increases with age. There is a significant effect of gender on the risk of development of HCC. The worldwide male to female incidence ratio is $2.7: 1$.

\section{IMPACT OF DIABETES AS RISK FACTOR IN HEPATOCELLULAR CARCINOMA}

Diabetes mellitus (DM) is a complex metabolic condition defined by the level of hyperglycemia giving rise to risk of micro vascular or macro vascular complications. ${ }^{50}$ Diabetes mellitus is identified as a risk factor for HCC. DM is shown to increase the risk of HCC by two to four folds even after adjusting for other predisposing factors.

The prevalence of diabetes in India is around 10\% i.e. 31 million people are suffering from diabetes and this number will increase to 80 million by year $2030 .{ }^{51,52}$ Indian people develop diabetes at younger age, lower degree of obesity and have increased risk of chronic diabetic complications. Asians have strong genetic susceptibility for type II diabetes. ${ }^{51,53}$

The relation between the diabetes and liver disease can be in three different ways-1) diabetes contributing or causing liver disease 2) risk factors for liver disease and diabetes are similar and 3) liver disease causing diabetes.

Diabetes is associated with more advanced HCC and poor outcome has been reported in prospective case control study. Diabetes appears to increase the recurrence of HCC after potentially curative therapy regardless of etiology of liver disease. ${ }^{51,54-56}$

Cirrhosis is associated with impaired glucose tolerance (GT) in more than $80 \%$ of the patients. ${ }^{57,58}$ Overt diabetes is seen around $20 \%$ of cirrhotics. Insulin resistance is a feature in patients with liver cirrhosis in the absence of diabetes. Pathogenesis of diabetes and cirrhosis includes peripheral and hepatic insulin resistance and decreased beta cell function (Figure 1). Increased mortality and increased risk of HCC has been shown in patients of cirrhosis who develop diabetes. ${ }^{54}$

Type II DM is common in Hepatitis C (HCV) infection as compared to the controls. ${ }^{59}$ In India the prevalence of

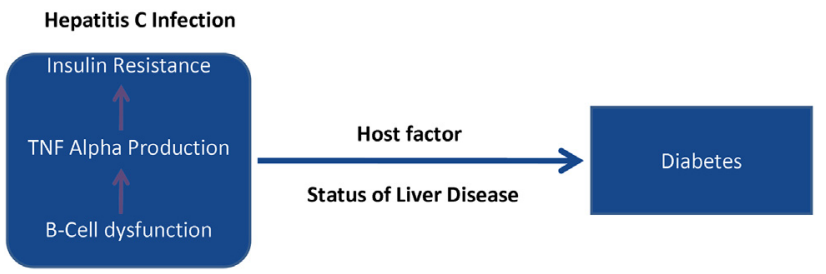

Figure 1 Hepatitis $\mathrm{C}$ and diabetes mellitus. ${ }^{67}$ 


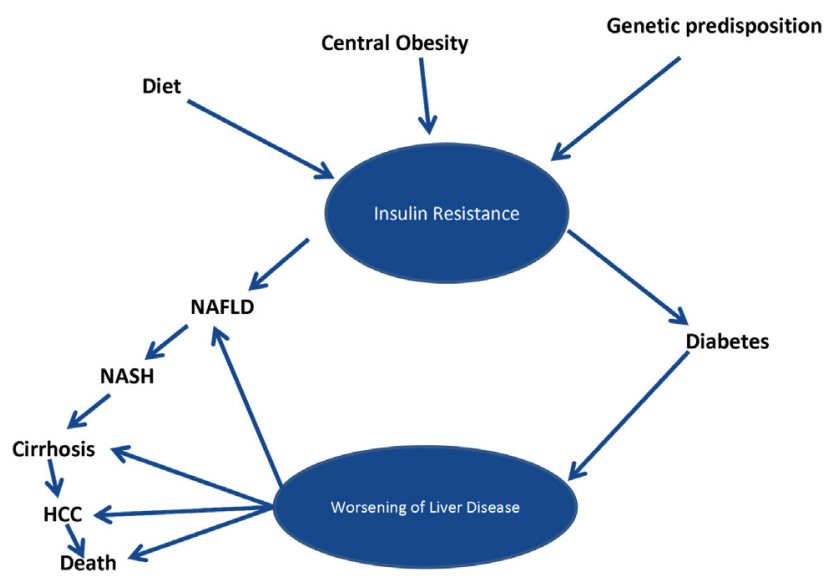

Figure 2 Spectrum of relationship between NAFLD and diabetes. ${ }^{64}$

$\mathrm{HCV}$ ranges from $0.3 \%$ to $4 \%$ in general population while prevalence of DM is around $10 \%$. An increased prevalence of DM in patients of HCV as compared to the patients with hepatitis B and controlled population has been demonstrated in a prospective study. In non-cirrhotic patients increased prevalence is also seen in chronic HCV infections and hence HCV infection may be a predisposing factor for development of DM in Indian population in addition to the presence of other risk factors for DM. $\mathrm{HCV}$ is associated with peripheral and hepatic insulin resistance in non obese, non diabetic patients with chronic HCV infection was reported by Lawson et al $1986 .{ }^{60}$

Lawson et $\mathrm{al}^{60}$ revealed the relationship of DM with HCC in which he surprisingly found a four-fold excess of diabetic patients among the group with HCC. The association between DM and HCC was found to be modified by hepatitis virus infection, heavy alcohol consumption, and other known risk factors. ${ }^{51,61-63}$ Fujino et al $2001^{61}$ found that the relative risk (RR) of DM for primary liver cancers was 2.06 (95\% CI, 1.014.19) after adjustment for smoking, alcohol, and diseases associated with liver cancer in a prospective study of diabetes and liver cancers in Japan. Diabetes increased the risk of liver cancers in patients with hepatitis and/or cirrhosis and it was concluded and confirmed by a few subsequent reported studies, although the modified factors were different in different studies. ${ }^{51,62,63}$ Ei-Serag et $\mathrm{al}^{54}$ also demonstrated that DM was also shown to increase the risk of primary liver cancers only in the presence of other risk factors such as hepatitis C or B, or alcoholic cirrhosis. In a cohort study, Lai et $\mathrm{al}^{63}$ found that the association between type $2 \mathrm{DM}$ and incidence of HCC was modified by HCV status after controlling for age, sex, HBV, HCV, smoking, and alcohol consumption. However, the association was only statistically significant (an adjusted hazard ratio of 2.08) for being $\mathrm{HCV}$ negative. DM is a "true" independent risk factor for HCC has been demonstrated.
The strong epidemiological evidence suggested that the risk of chronic liver disease, cirrhosis, HCC and increased mortality due to liver disease has been found in patients of diabetes compared to the controlled population. There is an evidence for increased incidence of acute liver failure in patients with diabetes who are on anti-hyperglycemic therapy. ${ }^{51,54,55}$

Most common form of liver disease in patients with diabetes is non-alcoholic fatty liver disease (NAFLD) (Figure 2). $20-50 \%$ patients with NAFLD have diabetes. Diabetic patients with NAFLD at are increased risk of advanced liver disease, cirrhosis and HCC. NAFLD is common from liver disease in diabetics. Both share common pathogenesis i.e. insulin resistance. NAFLD is precursor of diabetes. Diabetes is marker of progressive NAFLD leading to cirrhosis, HCC and increased mortality. ${ }^{35,51}$

Diabetes and obesity can cause hepatic inflammation, leading to oxidative stress and lipid peroxidation of the phospholipid constituents of hepatocyte and intracellular membranes, resulting in hepatocyte injury and necrosis, and subsequently HCC. ${ }^{64}$ Chen et.al ${ }^{47}$ found that extreme obesity (body mass index $\geq 30 \mathrm{~kg} / \mathrm{m}^{2}$ ) was independently associated with a 4-fold risk of HCC among anti-HCVseropositive subjects and a 2 -fold risk in persons without HBV and HCV infections, after controlling for other metabolic components, but not in HBsAg-seropositive subjects. Diabetes was associated with HCC in the patients with $\mathrm{HBV}, \mathrm{HCV}$, or without $\mathrm{HBV}$ and $\mathrm{HCV}$ infections, with the highest risk in those with HCV infection also found more than 100-fold increased risk in HBV or HCV carriers with both obesity and diabetes. Diabetes is an independent risk factor for prognosis after hepatic resection in patients with HCC. ${ }^{64}$ Diabetes does not affect the long-term survival in HCV-related HCC, which conflicted with one recent report conducted in Japan. It suggested that diabetes is a risk factor for the recurrence of HCV-related HCC and decreases the overall survival rates after surgical treatment. Poon et $\mathrm{al}^{65}$ also showed that diabetes did not increase the preoperative morbidity or mortality after resection of HCC and this was supported by an another study conducted by Huo et $\mathrm{al}^{64}$ in Taiwan, China.

\section{ROLE OF AFLATOXIN B CAUSES HEPATOCELLULAR CARCINOMA IN INDIA}

The incidence of HCC is reportedly low and varies from 0.2 to $1.9 \%$ in India. ${ }^{45}$ Age-adjusted incidence of HCC in rural and urban Indian populations is low compared to that in China, Japan and other Southeast Asian countries like India. ${ }^{45}$ The risk of HCC is greatly increased in chronic viral carriers exposed to other recognized risk factors, including exposure to aflatoxin B1 (AFB1). ${ }^{66,67}$

Aflatoxins, a secondary metabolite produced by Aspergillus flavus and Aspergillus parasiticus, are potent human carcinogens implicated in $\mathrm{HCC}^{68}$ and also it is proved to 
have a significant association with HCC in India. The impact seems to be a cumulative process, as revealed by the AFB1 deposits in HCC liver tissue, even though the serum levels were undetectable. ${ }^{68}$ Specific P450 enzymes in the liver metabolize aflatoxin into a reactive oxygen species (aflatoxin-8,9-epoxide), which may then bind to proteins and cause acute toxicity (aflatoxicosis) or to DNA to cause lesions that over time increase the risk of HCC. ${ }^{69}$

A causative role for aflatoxins in hepatocarcinogenesis in humans has been strongly suggested based on various epidemiological data. The degree of food contamination by aflatoxins and HCC incidence are closely and significantly correlated by Lin et al $1977 .{ }^{70}$ Carcinogenic activity of aflatoxin is attributed to covalent adduct formation by metabolically activated reactive intermediates with hepatocyte DNA, which could lead to mutations in the host genome. ${ }^{71}$ Mutations of the p53 gene on chromosome 17 have been frequently found in primary liver cancer. ${ }^{72-}$

74 This hotspot mutation was originally described in HCC from regions with high levels of dietary aflatoxins, and is considered a hallmark of AFB1. The molecular and cellular mechanisms underlying the carcinogenic effects of aflatoxin have also been investigated on numerous occasions in rodent models.

Aflatoxin appears to have a synergistic effect on Hepatitis C virus (HCV)-induced liver cancer. ${ }^{75-78}$ Other important causative factors in the development of HCC, in addition to HBV or HCV infection and aflatoxin exposure, are the genetic characteristics of the virus, alcohol consumption, and the age and sex of the infected person. ${ }^{75}$ Aflatoxin may play a causative role in $4.6-28.2 \%$ of all global HCC cases.

Henry et al $1999^{80} \&$ IPCS/WHO $1998^{81}$ reported that chronic HBV prevalence based on HBsAg seroprevalence is 2.4-4.7 in India. IPCS/WHO ${ }^{81}$ undertook an aflatoxinHCC risk assessment in 1998 to estimate the impact on population cancer incidence by moving from a hypothetical total aflatoxin standard of $20 \mathrm{ng} / \mathrm{g}$ to $10 \mathrm{ng} / \mathrm{g}$. Assuming that all food containing higher levels of aflatoxin than the standard was discarded and that enough maize and nuts remained to preserve consumption patterns, HCC incidence would decrease by about 300 cases per year per billion people, if the stricter aflatoxin standard were followed in nations with HBV prevalence of $25 \% .{ }^{82}$

The risk of liver cancer in individuals exposed to chronic HBV infection and aflatoxin is up to 30 times greater than the risk in individuals exposed to aflatoxin only. ${ }^{70}$ Wild and Gong ${ }^{83}$ presented HCC is a result of chronic aflatoxin exposure in persons with chronic Hepatitis B virus (HBV) infection. These two HCC risk factors-aflatoxin and $\mathrm{HBV}$, are prevalent in poor nations worldwide. Within these nations, there is often a significant urban-rural difference in aflatoxin exposure and HBV prevalence, with both these risk factors typically affecting rural populations more strongly.
Aflatoxin occurs in tropical and subtropical regions of the world in which grains such as rice are stored under tropical conditions. ${ }^{84}$ In the months after the monsoon in Southeast Asia, stored grains reportedly contain high levels of aflatoxin. The grains stored under such conditions increase the risk of development of HCC, as aflatoxin is a potent source of hepatocarcinogenesis. It has shown that the effects of exposure to aflatoxin and Hepatitis $B$ virus (HBV) infection are significantly associated with the risk of death due to liver cancer. ${ }^{71,85}$ Ross et $\mathrm{al}^{86}$ have revealed a strong statistical correlation between aflatoxin ingestion and incidence of HCC in several areas of the world.

Murugavel et al ${ }^{67}$ from South India revealed that liver biopsies of HCC, the aflatoxin was detected in $58 \%$ of cases and no cirrhosis case was found to be positive for aflatoxin. It was therefore the patients had a possible history of AFB1-contaminated foodstuffs, which has acted either as a primary or additional risk factor for HCC. $58.1 \%$ of HCC cases showed aflatoxin in liver biopsies was reported, but all cirrhosis cases were negative for aflatoxin. Furthermore, $68.8 \%$ of HBsAg-negative HCC cases and $46.1 \%$ of HBsAg positive patients were positive for aflatoxin in liver biopsy and hence proved that aflatoxins have a significant association with HCC in India.

A strong association between baseline levels of urinary AFB metabolites, especially the major AFB-DNA adduct, and HCC risk in study subjects has been demonstrated in the biomarker-based, prospective Shanghai Cohort Study. ${ }^{46,49,87}$ Several ecological studies have also shown a significant association between dietary aflatoxin exposure and hepatocarcinogenesis ${ }^{88,89}$ along with classification of aflatoxin as a group 1 human carcinogen. ${ }^{90}$ However, the association has also been refused on several occasions. ${ }^{91-}$ 93 This inconsistency may be due to the difficulty of

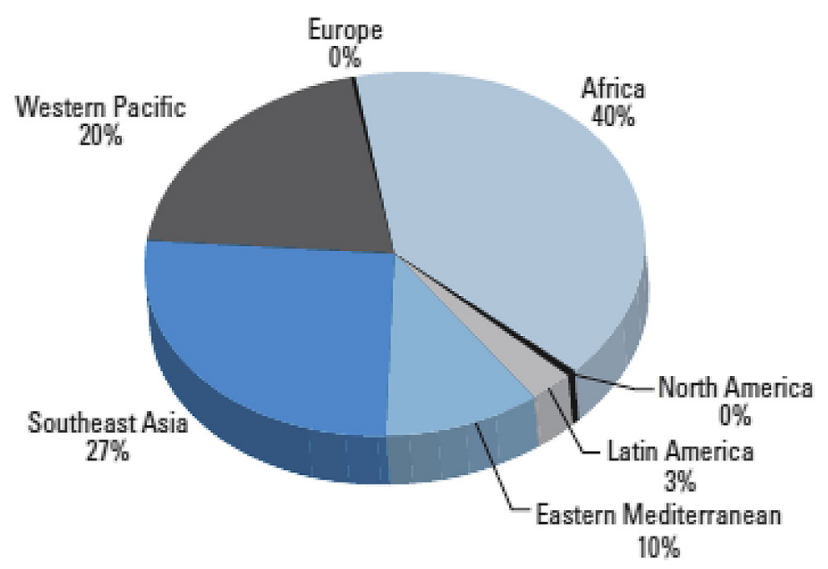

Figure 3 Distribution of HCC cases attributable to aflatoxin in different regions of the world and the distribution of $\mathrm{HCC}$ cases in South East Asia is $27 \% .^{94}$ 
accurate assessment of aflatoxin exposure at the population or individual level.

\section{SUMMARY}

HBV infection, HBV infection with Aflatoxin exposure, viral infection and alcohol consumption leading to overt cirrhosis of the liver, alcohol consumption leading to cirrhosis of the liver with viral infection are the predominant risk factor for the development of HCC in India. Therefore prevention of viral infection by universal vaccination against hepatitis virus should be adopted in India. Effective antiviral therapy of chronic hepatitis virus (hep B $\& \mathrm{C}$ virus) is very important measure to prevent HCC. Hepatocellular carcinoma surveillance program is a necessary measure in India. All patients with diabetes and cirrhosis are recommended for HCC surveillance. HCC screening is also recommended for high risk patients with chronic hepatitis $B$ and $C$ especially those aged more than 40 years and serum viral load greater than their optimum limit. Preventing alcoholic liver diseases should prevent some cases of HCC in India. Prevention of fungal contamination of grains and ground crops to prevent basically Aflatoxin exposure are important measures to prevent liver diseases and HCC among those at risk, particularly HBV infected persons in endemic regions of the country (Figure 3).

\section{CONFLICTS OF INTEREST}

The author has none to declare.

\section{REFERENCES}

1. Di Bisceglie AM, Rustgi VK, Hoofnagle JH, Dusheiko GM, Lotze MT. Hepatocellular carcinoma. Ann Intern Med. 1988;108:390-401.

2. Chisari FV, Klopchin K, Moriyama T, et al. Molecular pathogenesis of hepatocellular carcinoma in hepatitis B virus transgenic mice. Cell. 1989;59:1145-1156.

3. Idilman R, De Maria N, Colantoni A, Van Thiel DH. Pathogenesis of hepatitis B and C-induced hepatocellular carcinoma. J Viral Hepat. 1998;5(5):285-299.

4. Feitelson M. Hepatitis-B $x$-antigen in the pathogenesis of hepatocellular-carcinoma (review). Oncol Rep. 1995 Mar;2(2): 193-202.

5. Paterlini P, Driss F, Pisi E, et al. Persistence of hepatitis B and C viral genomes in primary liver cancers from HBsAg negative patients: a study of a low endemic area. Hepatology. 1993;17:20-29.

6. Bréchot C, Minami M, De Mitri S, Paterlini P. Hepatitis B and C viruses in hepatitis B surface antigen negative hepatocellular carcinoma patients. Princess Takamatsu Symp. 1995;25:199-209.

7. Takano S, Yokosuka O, Imazeki F, Tagawa M, Omata M. Incidence of hepatocellular carcinoma in chronic hepatitis B and C: a prospective study of 251 patients. Hepatology. 1995 Mar;21(3):650-655.

8. Tsukuma H, Hiyama T, Tanaka S, et al. Risk factors for hepatocellular carcinoma among patients with chronic liver disease. N Engl J Med. 1993 Jun 24;328(25):1797-1801.

9. Nalpas B, Martin S, Fontaine H, et al. Impact of medical recommendations on alcohol consumption in HCV positive patients. J Hepatol. 2001;35(2):312-313.
10. Guptan RC, Thakur V, Sarin SK, Banerjee K, Khandekar P. Frequency and clinical profile of precore and surface hepatitis B mutants in Asian-Indian patients with chronic liver disease. Am J Gastroenterol. $1996 \mathrm{Jul} ; 91(7): 1312-1317$.

11. World Gastroenterology Organisation Global GuidelineHepatocellular Carcinoma (HCC): A Global Perspective. November 2009.

12. Okuda K, Fujimoto I, Hanai A, Urano Y. Changing incidence of hepatocellular carcinoma in Japan. Cancer Res. 1987;47:4967-4972.

13. Okuda K. New trends in hepatocellular carcinoma. Int J Clin Lab Res. 1993;23(4):173-178.

14. Nellithady GS, Anila K, Kumar KK, Kaveri H. Lack of association of chronic liver disease in patients with oral Lichen planus. J Carcinog Mutagene. 2010;1:113.

15. Cariani E, Lasserre C, Seurin D, et al. Differential expression of insulin-like growth factor II mRNA in human primary liver cancers, benign liver tumors, and liver cirrhosis. Cancer Res. 1988 Dec 1;48(23):6844-6849.

16. Kinami Y, Takashima S, Miyazaki I. Hepatic resection for hepatocelIular carcinoma associated with liver cirrhosis. World J Surg. 1986 Apr;10(2):294-301.

17. Liu ZM, Li LQ, Peng, et al. Hepatitis B virus infection contributes to oxidative stress in a population exposed to aflatoxin B1 and highrisk for hepatocellular carcinoma. Cancer Lett. 2008;263(2): 212-222.

18. Oka H, Kurioka N, Kim K, et al. Prospective study of early detection of hepatocellular carcinoma in patients with cirrhosis. Hepatology. 1990 Oct;12(4 Pt 1):680-687.

19. Colombo M, de Franchis R, Del Ninno E, et al. Hepatocellular carcinoma in Italian patients with cirrhosis. N Engl J Med. 1991 Sep 5;325(10):675-680.

20. Yu MW, Hsu FC, Sheen IS, et al. Prospective study of hepatocellular carcinoma and liver cirrhosis in asymptomatic chronic hepatitis B virus carriers. Am J Epidemiol. 1997:145(11):1039-1047.

21. Li H, Wang G, Wang A, Tong W, Zhang Y. Alcohol consumption and risk of type 2 diabetes in Mongolian population, inner Mongolia, China. J Diabetes Metab. 2011;2:116.

22. Austin H, Deizell E, Grufferman, et al. A case-control study of hepatocellular carcinoma and the hepatitis B virus, cigarette smoking and alcohol consumption. Cancer Res. 1986;46:962-966.

23. Ozturk M, Bressae B, Puisieux, et al. P53 mutation in hepatocellular carcinoma after aflatoxin exposure. Lancet. 1991;338: 113-122.

24. Lunn RM, Zhang Y-J, Wang, et al. P53 mutations, chronic hepatitis $B$ virus infection, and aflatoxin exposure in hepatocellular carcinoma in Taiwan. Cancer Res. 1997;57:3471-3477.

25. Chen SY, Chen CJ, Chou SR, et al. Association of aflatoxin B(1)albumin adduct levels with hepatitis B surface antigen status among adolescents in Taiwan. Cancer Epidemiol Biomarkers Prev. 2001;10(11):1223-1226.

26. Sarin SKTV, Guptan RC, Saigal S, Malhotra V, Thyagarajan SP, Das BC. Profile of hepatocellular carcinoma in India: an insight into the possible etiologic associations. J Gastroenterol Hepatol. 2001;16:666-673.

27. Singh S, Sarin SK. Distribution of hepatitis $C$ virus genotypes in patients with chronic hepatitis C infection in India. Indian J Med Res. 2004:119145-119148.

28. Edman JC, Gray P, Valenzuela P, et al. Integration of hepatitis B virus sequences and their expression in human hepatoma cell. Nature. 1980;286:535-538.

29. Ishikawa T, Ishibashi J, Yamashita K, et al. Non-thermal effects of far-infrared Ray (FIR) on human hepatocellular carcinoma cells HepG2 and their tumors. J Cancer Sci Ther. 2009;1:78-82.

30. Kaneko M, Suzuki H, Watanabe H, Oda E, Aizawa Y. Metabolic syndrome is a poor predictor of incident diabetes compared with 
hemoglobin A1C (Hba1c) in a general Japanese population. J Diabetes Metab S. 2011:2.

31. Ramachandra S. Do we need yet another Insulin? J Diabet Metabol. 2011;2:0e4.

32. Takasaki S. Mitochondrial haplogroups associated with Japanese centenarians, Alzheimer's patients, Parkinson's patients, type 2 diabetes patients, healthy non-obese young males, and obese young males. J Proteomics Bioinform. 2011;4:106-112.

33. Kablan A, Saunders RA, Szkudlarek-Mikho M, et al. Prieurianin causes weight loss in diet-induced obese mice and inhibits adipogenesis in cultured preadipocytes. J Diabetes Metab. 2010;1:101.

34. Shanker JH, Mahmood SE, Joshi MC, Shaifali I. Obesity indices amongst diabetics in an urban population of western Nepal. J Diabetes Metab. 2011;2:134.

35. Amarapurkar DN, Amarapurkar AD. Non-alcoholic steatohepatitis: clinicopathological profile. J Assoc Physic India. 2000;48:311-313.

36. Kumar M, Kumar R, Hissar SS, et al. Risk factors analysis for hepatocellular carcinoma in patients with and without cirrhosis: a casecontrol study of 213 hepatocellular carcinoma patients from India. J Gastroenterol Hepatol. Jul 2007;22(7):1104-1111. Epub 2007 Jun 7.

37. Asim M, Sarma MP, Thayumanavan L, Kar P. Role of aflatoxin B1 as a risk for primary liver cancer in north Indian population. Clin Biochem. 2011 Oct;44(14-15):1235-1240.

38. Asim M, Malik A, Sarma MP, et al. Hepatitis B virus BCP, Precore/ core, $\mathrm{X}$ gene mutations/genotypes and the risk of hepatocellular carcinoma in India. J Med Virol. July 2010;82(7):1115-1125.

39. Pujol FH, Navas MC, Hainaut P, Chemin I. Worldwide genetic diversity of HBV genotypes and risk of hepatocellular carcinoma. Cancer Lett. 2009 Dec 1;286(1):80-88.

40. Vivekanandan P, Torbenson M, Ramakrishna B. Hepatitis B virusassociated hepatocellular carcinoma from India: role of viral genotype and mutations in CTNNB1 (beta-catenin) and TP53 genes. J Gastrointest cancer. 2011;42(1):20-25.

41. Sarma Manash Pratim, Asim Mohammad, Medhi Subhash, Bharathi Thayumanavan, Diwan Richa, Kar Premashis. Viral genotypes and associated risk factors of hepatocellular carcinoma in India. Cancer Biol Med. 2012;9:172-181.

42. Paul Shashi Bala, Sreenivas Vishnubhatla, Gulati Manpreet Singh, et al. Incidence of hepatocellular carcinoma among Indian patients with cirrhosis of liver: an experience from a tertiary care center in northern India. Indian J Gastroenterol. 2007;26 (Nov-Dec).

43. Tripathy Anuradha S, Shankarkumar U, Chadha Mandeep S, Ghosh Kanjashkya, Arankalle Vidya A. Association of HLA alleles with hepatitis C infection in Maharashtra, western India. Indian J Med Res. November 2009;130:550-555.

44. Anitha S. Assessment of Aflatoxin Exposure Among Indian Population. PhD thesis. Nizam's Institute of Medical Sciences; 2011 http://oar.icrisat.org/id/eprint/5268.

45. Dhir V, Mohandas KM. Epidemiology of digestive cancer in IndiaIII: liver. Indian J Gastroenterol. 1998;17:100-103.

46. Chen CJ, Zhang YJ, Lu SN, Santell RM. Aflatoxin B1 DNA adducts in smeared tumor tissue from patients with hepatocellular carcinoma. Hepatology. 1992;16:1150-1155.

47. Chen C, Huang M, Yang I, et al. Prevalence and risk factors of nonalcoholic fatty liver disease in an adult population of taiwan: metabolic significance of nonalcoholic fatty liver disease in nonobese adults. J Clin Gastroenterol. 2006:40:745-752.

48. IARC (International Agency for Research on Cancer). Some traditional herbal medicines, some mycotoxins, naphthalene and styrene. IARC Monogr Eval Carcinog Risks Hum. 2002;82:171-300.

49. Wang JS, Huang T, Su J, et al. Hepatocellular carcinoma and aflatoxin exposure in Zhuqing Village, Fusui County, People's Republic of China. Cancer Epidemiol Biomarkers Prev. 2001;10:143-146.
50. Yoon KH, Lee JH, Kim JW, et al. Epidemic obesity and type II diabetes in Asia. Lancet. 2006;368:1681-1688.

51. Amarapurkar DN, Patel ND. Increased prevalence of type II diabetes mellitus in hepatitis C virus infection in Western India. Trop Gastroenterol. 2008;29:148-152. troenterol 2006;40:58-76.

52. Definition and Diagnosis of Diabetes Mellitus. WHO; 2008.

53. Amarapurkar DN, Das HS. Chronic liver disease in diabetes mellitus. Trop Gastroenterol. 2002;23:3-5.

54. El-Serag HB. Hepatocellular carcinoma: recent trends in the United States. Gastroenterology. 2004;127:S27-S34.

55. Regimbeau JM, Colombat M, Mognol P, et al. Obesity and diabetes as a risk factor for hepatocellular carcinoma. Liver Transpl. 2004;10:S69-S73.

56. Baig N, Herrine S, Rubin R. Liver disease and diabetes mellitus. Clin Lab Med. 2001;21:193-207.

57. Petrides AS. Liver disease and diabetes Mellitus. Diabetes Rev. $1994 ; 2: 2-18$

58. Holstein A, Hinze S, Thieben E. Clinical implication of hepatogenous diabetes in liver cirrhosis. J Gastroenterol Hepatol. 2002;17:677-684.

59. Vanni E, Abate ML, Gentilcore, et al. Sites of insulin resistance in non obese, non diabetic patients with chronic hepatitis C. Hepatology. 2009;50:697-706.

60. Lawson DH, Gray JM, McKillop C, Clarke J, Lee FD, Patrick RS. Diabetes mellitus and primary hepatocellular carcinoma. Q J Med. 1986;61:945-955.

61. Fujino Y, Mizoue T, Tokui N, Yoshimura T. Prospective study of diabetes mellitus and liver cancer in Japan. Diabetes Metab Res Rev. 2001;17:374-379.

62. Li FQ, Yoshizawa T, Kawamura O, Luo XY, Li YW. Aflatoxins and fumonisins in corn from the high-incidence area for human hepatocellular carcinoma in Guangxi, China. J Agric Food Chem. 2001;49(8):4122-4126.

63. Lai MS, Hsieh MS, Chiu YH, Chen TH. Type 2 diabetes and hepatocellular carcinoma: a cohort study in high prevalence area of hepatitis virus infection. Hepatology. 2006;43:1295-1302.

64. Huo TI, Wu JC, Lui WY, et al. Diabetes mellitus is a recurrenceindependent risk factor in patients with hepatitis B virus-related hepatocellular carcinoma undergoing resection. Eur J Gastroenterol Hepatol. 2003;15:1203-1208.

65. Poon RT, Fan ST, Wong J. Does diabetes mellitus influence the perioperative outcome or long term prognosis after resection of hepatocellular carcinoma? Am J Gastroenterol. 2002;97:1480-1488.

66. Marrero JA, Fontana RJ, Fu S, Conjeevaram HS, Su GL, Lok AS Alcohol, tobacco and obesity are synergistic risk factors for hepatocellular carcinoma. J Hepatol. 2005;42:218-224.

67. Murugavel KG, Naranatt PP, Shankar EM, et al. Prevalence of aflatoxin B1 in liver biopsies of proven hepatocellular carcinoma in India determined by an in-house immunoperoxidase test. J Med Microbiol. 2007;56:1455-1459.

68. Groopman JD, Kensler TW, Wild CP. Protective interventions to prevent aflatoxin-induced carcinogenesis in developing countries. Annu Rev Public Health. 2008;29:187-203.

69. Van Rensburg SJ, Cook-Mozaffari P, Van Schalkwyk DJ, Van Der Watt JJ, Vincent TJ, Purchase IF. Hepatocellular carcinoma and dietary aflatoxin in Mozambique and Transkei. $\mathrm{Br} J$ Cancer. 1985;51:713-726.

70. Lin JK, Mille JA, Miller EC. 2,3-Dihydro-2-(guan-7-yl)-3-hydroxyaflatoxin B1, a major acid hydrolysis product of aflatoxin B1DNA or ribosomal RNA adducts formed in hepatic microsomemediated reactions in rat liver in vivo. Cancer Res. 1977;37:4430-4438.

71. Bressac B, Kew M, Wands J, Ozturk M. Selective G to T mutations of p53 gene in hepatocellular carcinoma from southern Africa. $\mathrm{Na}$ ture. 1991;350:429-431. 
72. Caldwell SH, Oliveira CPMS, de Lima VMR, Park SH Chapter in International update on Hepatology. In: Bataller Ramon, ed. NASH, Cryptogenic Cirrhosis and Hepatocellular Carcinoma. Permanyer Publication; 2007.

73. Laurent-Puig P, Legoix P, Bluteau $\mathrm{O}$, et al. Genetic alterations associated with hepatocellular carcinomas define distinct pathways of hepatocarcinogenesis. Gastroenterology. 2001;120:1763-1773.

74. McMahon G, Davis EF, Huber L, Kim Y, Wogan GN. Characterization of c-Ki-ras and $\mathrm{N}$-ras oncogenes in aflatoxin B1-induced rat liver tumors. Proc Natl Acad Sci U S A. 1990;87:1104-1108.

75. Kirk GD, Lesi OA, Mendy M, et al. 249(ser) P53 mutation in plasma DNA, hepatitis B viral infection, and risk of hepatocellular carcinoma. Oncogene. 2005;24(38):5858-5867.

76. Kuang S-Y, Lekawanvijit S, Maneekarn N, et al. Hepatitis B 1762T/ 1764A mutations, hepatitis C infection, and codon 249 p53 mutations in hepatocellular carcinomas from Thailand. Cancer Epidemiol Biomarkers Prev. 2005;14(2):380-384.

77. Wild CP, Jiang YZ, Sabbioni G, Chapot B, Montesano R. Evaluation of methods for quantification of aflatoxin-albumin and their application to human exposure assessment. Cancer Res. 1990;50:245-251.

78. Behal R, Jain R, Behal KK, Bhagoliwal A, Aggarwal N, Dhole TN. Seroprevalence and risk factors for hepatitis $B$ virus infection among general population in Northern India. Arq Gastroenterol. 2008;45(2):137-140.

79. Liu Yan, Wu Felicia. Global Burden of aflatoxin-induced hepatocellular carcinoma: a risk assessment. Environ Health Perspect. 2010 June;118(6):818-824.

80. Henry SH, Bosch FX, Troxell TC, Bolger PM. Policy forum: public health. Reducing liver cancer-global control of aflatoxin. Science. 1999;286(5449):2453-2454.

81. International Programme on Chemical Safety and WHO. International Programme on Chemical Safety. Safety Evaluation of Certain Food Additives and ContaminantsIn: WHO Food Additives Series 40. IPCS/WHO 1998; 1998. Available: http://www.inchem.org/ documents/jecfa/jecmono/v040je01.htm.

82. Strosnider H, Azziz-Baumgartner E, Banziger M, et al. Workgroup report: public health strategies for reducing aflatoxin exposure in developing countries. Environ Health Perspect. 2006;114:18981903.

83. Wild CP, Gong YY. Mycotoxins and human disease: a largely ignored global health issue. Carcinogenesis. 2010;31:71-82.

84. Busby Jr WF, Wogan GN. Aflatoxins. In: Searle CE, ed. Chemical Carcinogens. 2nd ed. vol. 2. Washington, DC: American Chemical Society; 1984:945-1136.

85. Hsu IC, Metcalf RA, Sun T, Welsh JA, Wang NJ, Harris CC. Mutational hotspot in the p53 gene in human hepatocellular carcinomas. Nature. 1991;350:427-428.

86. Ross RK, Yuan JM, Yu MC, et al. Urinary aflatoxin biomarkers and risk of hepatocellular carcinoma. Lancet. 1992;339:943-946.

87. Williams JH, Phillips TD, Jolly PE, Stiles JK, Jolly CM, Aggarwal D. Human aflatoxicosis in developing countries: a review of toxicology, exposure, potential health consequences, and interventions. Am J Clin Nutr. 2004;80:1106-1122.

88. Peers F, Bosch X, Kaldor J, Linsell A, Pluijmen M. Aflatoxin exposure, hepatitis B virus infection and liver cancer in Swaziland. Int J Cancer. 1987 May 15;39(5):545-553.

89. Yeh FS, Yu MC, Mo CC, Luo S, Tong MJ, Henderson BE. Hepatitis B virus, aflatoxins and hepatocellular carcinoma in southern Guangxi, China. Cancer Res. 1989;49:506-2509.

90. IARC. Aflatoxins. IARC Monogr Eval Carcinog Risks Hum. 1993;56:245-395.

91. Lam KC, Yu MC, Leung JWC, Henderson BE. Molecular viral oncology of hepatocellular carcinoma. Oncogene. 1982;22: 5093-5107.

92. Lu SN, Lin TM, Chen CJ, et al. A case-control study of primary hepatocellular carcinoma in Taiwan. Cancer. 1988;62:2051-2055.

93. Campbell TC, Chen J, Liu C, Li J, Parpia B. Characterization of C-Kiras and $\mathrm{N}$-ras oncogenes in aflatoxin B1-induced rat liver tumors. Proc Natl Acad Sci U S A. 1990;87:1104-1108.

94. Perz Joseph F, Armstrong Gregory L, Farrington Leigh A, Hutin Yvan JF, Bell Beth P. The contributions of hepatitis B virus and hepatitis C virus infections to cirrhosis and primary liver cancer worldwide. J Hepatol. 2006;45:529-538. 